\title{
Enhancing public mental health and wellbeing through creative arts participation
}

\section{Background}

As a mental health nurse with a lifelong interest in creativity and the creative arts I have, over a number of years, been exploring creative approaches to fostering wellbeing in both my clinical practice with service users and carers and in various educational, leadership and managerial roles in healthcare. This practice has informed, and been informed by, my writings. My most recent book, Creativity, Wellbeing and Mental Health Practice (Gillam, 2018), distils my findings in this area. While my focus has been on the wellbeing of the providers and users of mental health services, implicit in all of this is an assumption that the mental health and wellbeing of the wider community can be enhanced through creative activity. This article seeks to explore this aspect further. My particular interest is in music and creative writing but what I discuss can apply just as much to any creative arts activity.

\section{Good for everyone}

Shaun McNiff, a pioneer of art therapy and professor of expressive therapies, suggests: "Art therapy work within the mental health field has started a process that is good for everyone. Arts heals all of us - not just the mentally ill" (McNiff, 2004: p.xi.) Of course, this implies that "the mentally ill" are a distinct group within society, but there is a view that we are all more or less mentally ill or well. Keyes (2002) provides a useful conceptualisation in which there is a continuum of mental health (ranging from poor mental health to good mental health) and a continuum of wellbeing (from languishing to flourishing) (see Table 1.) The two continua are related but distinct so that, for example, a person with no diagnosable mental illness may nevertheless be languishing while another person, despite having a high level of mental illness, may be flourishing. 
According to Keyes, we are flourishing - or thriving - when we are enjoying positive emotion and good psychological and social functioning, whereas languishing is associated with emptiness, stagnation and despair. Languishing is not in itself pathological but is seen as a risk factor for mental illness whereas flourishing is seen as a protective factor against mental illness. So, when McNiff (2004) asserts that art is good and healing for everyone, we might translate this as: art can both help in recovery from mental illness and promote wellbeing for all.

These are precisely the findings of Stickley, Wright and Slade (2018) who found strong evidence of a positive effect of participatory arts activities on the health and wellbeing of the general population whilst also recommending them to people living with mental health problems. Since these activities enhance connectedness and improve hope they also support recovery.

\section{Mental health, wellbeing and the arts}

The policy document No Health Without Mental Health (DoH, 2011) offered one definition of wellbeing: "a positive state of mind and body, feeling safe and able to cope, with a sense of connection with people, communities and the wider environment" (p.90). If we apply this to the arts, it is easy to see how participation in arts activities might promote both a positive state of mind and body and a sense of connection with people, communities and the wider environment. This definition also reminds us that there is a responsibility on organisers and facilitators of such activities to ensure people feel safe.

Participatory arts are one aspect of the role of arts in health. Griffiths (2003) identified three key themes:

- The place of arts and creativity in promoting community health

- The use of artworks in clinical settings such as hospitals

- The therapeutic value of participation in the arts, particularly for those considered to be socially excluded. 


\section{Arts for social inclusion}

Social inclusion is a term that has perhaps fallen out of usage under more recent governments but, in 2004, the UK's New Labour government had a Social Inclusion Programme which identified access to recreational activities - including participation in the arts - as essential to promoting the social inclusion of people with mental health needs (ODPM, 2004). Their report argued that arts activities could have a therapeutic role and also help people reintegrate into society by increasing self-esteem, confidence and social networks.

Leckey (2011) reviewing the literature relating to the therapeutic effectiveness of creative activities on mental wellbeing, concluded that, while the scope of creative arts and their effects on mental wellbeing was impressive - in terms of the number of people participating - there was no clear evidence that such participation resulted in social benefits. That said, she identified eleven studies which showed a direct link between creative arts, mental health and mental wellbeing. These interventions ranged from visual arts, crafts and writing to photography and the performing arts.

\section{Arts as a protective factor}

According to Griffiths (2003) the mental health benefits of arts and creativity are three-fold. They

- strengthen psychosocial, life and coping skills of the individual

- increase social support as a buffer against adverse life events

- Increase access to resources and services that protect mental well-being.

From this analysis it might be thought that the benefits of arts participation are linked to simply taking part, making new friends and learning new skills, (in other words social and recreational aspects, rather than any specific artistic or creative element.) However, the unique opportunity for self-expression also seems to be important, and I have certainly found this in my own work using music and creative writing. 


\section{Arts in Health compared with creative arts therapies}

It is important to distinguish between creative arts therapies and Arts in Health. Arts therapies are used in direct therapeutic work as part of the clinical provision whereas Arts in Health activities either create access to the arts for the disenfranchised or complement health practice (Jones, 2005). Creative arts therapies and the Arts in Health movement have developed side by side. So, while music therapy and others arts therapies have become more and more professionalised (with increasingly advanced training courses, professional bodies, journals and bodies of research) there has arisen a parallel movement of community arts. This movement is less about using arts to treat mental health problems and more about user-involvement and empowerment. It involves artists - and sometimes mental health workers like myself who are not professional creative arts therapists - and also involves service users and communities.

\section{Participatory arts}

Some of the more recent literature uses the term participatory arts. Participatory arts activities are typically facilitated by artists (rather than creative arts therapists or any other health professional.) They involve active participation in the given art form. Stickley, Wright and Slade (2018) found strong evidence that arts participation has a positive effect on health and wellbeing. Participation in activities such as music, dance, creative writing, handicrafts and drama produced effects including improvements in

- emotional, social, physical and organisational wellbeing (Jindal-Snape et al., 2014),

- resilience in young people (Macpherson et al., 2012)

- community participation and reduced societal stigma in older people (McLean et al., 2011)

- creativity and personal development (Lewis et al., 2016).

Music-based therapeutic activity appears to be particularly beneficial for people with dementia. A recent Cochrane review of the evidence found music-based interventions probably reduce anxiety and depressive symptoms in people with dementia in institutional care and also improve their emotional well-being (van der Steen et al., 2018). 


\section{Community music}

The community music movement upholds the belief that everyone should have the opportunity to make music and explore their musical potential. It is concerned with the value of music and the arts, not just to individuals, but to communities. Rather than using music therapists, community music initiatives often employ professional musicians who work with people with any level of musical experience (or none at all) to create and sometimes to perform or record music, in a wide range of settings including schools, youth clubs and day centres as well as more traditional performance venues. Community music organisations act as initiating and developing agencies for innovative participatory music and work towards improving access to music-making.

Key features in the philosophy of the community music movement include:

- a belief in providing opportunities for individuals and communities

- inclusiveness

- forging links with community settings

- promoting innovation and participation

- facilitating access to creativity for people with disabilities

- potentially providing the means for the resulting music to reach a wider audience.

The above list overlaps considerably with Griffiths's (2003) list of the mental health benefits of participation in creative arts activity and with the effects on health and wellbeing identified by Stickley, Wright and Slade (2018).

\section{Music Workshops}

My own Music Workshop Project was one example of an initiative which, almost organically, grew away from a 'therapy' model and towards a 'community music' or participatory arts model (Gillam, 2002). The project, based in Kidderminster, Worcestershire, had two main aims - firstly, to help people with mental health problems by involving them in musical activities, and secondly, to present a more positive image of mental health to the public, in order to reduce fear and stigma. The backbone of the project was a monthly improvisational group session but out of these sessions grew the ambition to also produce and release CD 
albums.

The project provided regular opportunities for people with a range of mental health conditions to express themselves through music. Along with the therapeutic effects of being creative it aimed to encourage people to develop interpersonal skills through improvisational groupwork. From the start, the project was not intended for competent musicians. It did not set out to teach people to be proficient musicians but to promote an interest in making music and exploring its potential for personal expression and interpersonal communication. Moreover, unlike some other music-related groups offered by mental health services, the project was expressly not for passively listening to music but for actively creating it.

Since the original project ended some years ago I have changed roles several times and, in my most recent book, I wrote elegiacally about the Music Workshop Project, believing my days of therapeutic music-making were over. Serendipitously, however, I have more recently been invited by Dudley MIND (a local branch of the Mental Health charity) to facilitate a series of music workshop sessions for wellbeing. Although I remain a registered mental health nurse, I approach these sessions as participatory arts activities which I facilitate as a musician rather than as a nurse. In this context, I am a musical group leader or, as McNiff (2004) might more poetically describe it, the 'keeper' or 'caretaker' of the 'studio' or creative space. I have found it helpful, in being clear about my role, to identify with McNiff's view that: "As a 'keeper' or 'caretaker' of the studio, my primary function is to kindle the soul of the place, to maintain its vitality and its ability to engage people in highly individual ways..." (p.20). This is not how mental health nurses would typically describe their function though I would argue that, if nurses are to be truly concerned with the wellbeing of society (and not just the health of mental health service users) then they do need to be skilled at facilitating flourishing (Gillam, 2018.)

\section{Literature, writing, and storytelling for wellbeing}

Another way in which nurses can facilitate flourishing in communities is by having a greater 
understanding of the value of literature, writing and storytelling. Creative writing has been used in a surprisingly wide range of settings with an equally diverse range of client groups. With older adults it has been used in care homes and in poetry workshops as a preventative approach to cognitive decline (Swann, 2009; Saunders, 2007). In California, creative writing has helped women prisoners cope with incarceration and prepare for re-entry to society (Sparks, 2008) while in Australia it has been used as a means of fostering the wellbeing of GPs (Smith, 2008). In dual diagnosis residential treatment programmes it has been deployed as an intervention for those with alcohol problems, depression and impulse control disorders (Gillispie, 2003) while those working with disadvantaged adolescents have seen it as a means of enhancing young people's self-esteem and self-efficacy (Chandler, 1999).

This brief overview shows that creative writing activity in mental health and wellbeing is widespread. Across the whole age range from children to older adults and multifarious settings, and from community groups to care homes and prisons, it is seen as a means of

- treating a variety of existing mental health problems

- potentially preventing the development of difficulties

- promoting positive mental health and wellbeing in service users, as well as those who work with them.

According to Lepore and Smyth (2002) writing for therapy emerged out of the psychotherapeutic tradition of using expressive therapies for conditions associated with traumatic experiences. Writing can, they assert, "provide a method for expressing stressrelated thoughts and feelings nearly anywhere and without social repercussions" (p.6). The phrase "without social repercussions" chimes with my earlier observation that, if it is to enhance wellbeing, any participatory arts activities must provide a safe, supportive environment where people can share thoughts and experiences without fear of being judged.

\section{Expressive writing}

James Pennebaker, one of the pioneers of creative writing therapy, used a method called 
expressive writing. Participants were asked to write about personally upsetting experiences for twenty to thirty minutes each day for several days. In randomised controlled trials the expressive writing intervention was found to produce positive effects on a wide range of physical and mental health aspects (Pennebaker, 2002). These included reductions in:

- health centre visits

- $\quad$ self-reported illness

- depressive symptoms

- rheumatoid arthritis symptoms.

Pennebaker's studies also showed improvements in:

- the immune system

- lung functioning in asthma patients

- social relationships

- role functioning.

Pennebaker acknowledged that any attempt to pinpoint the essence of the technique is inherently vague but some of the aspects he felt were important were associated with the search for meaning, the creation of coherent stories about one's life and emotional awareness and expression.

\section{Bibliotherapy, therapeutic writing and poetry therapy}

In a review of the expressive and therapeutic uses of literature two nurse researchers, McArdle and Byrt (2001), found positive outcomes had been reported, with particular evidence of clinical effectiveness for bibliotherapy, poetry therapy and therapeutic writing. The meaning of these three different but overlapping areas of therapeutic uses of literature need further clarification here.

Bibliotherapy is "the therapeutic use of literature with guidance or intervention from a therapist" (Cohen, 1994, p.40). It involves enhancing the service user's knowledge and insight with literature related to illness or other difficulties, as well as fiction or poetry, as an adjunct to other interventions. 
Poetry therapy is less well-defined but involves the intentional use of poetry for healing and personal growth. Some definitions suggest it is synonymous (or almost synonymous) with bibliotherapy. For example, the National Association for Poetry Therapy describe it as "a specific and powerful form of bibliotherapy, unique in its use of metaphor, imagery, rhythm, and other poetic devices" (NAPT, 2017). Still more confusingly, others suggest the term "is used inclusively to refer not only to the use of published and original poems but also to the interactive use of literature (bibliotherapy) and therapeutic writing (journal therapy)" (LifeSpeaks Poetry Therapy, 2017). This seems to imply that poetry therapy is on the one hand a form of bibliotherapy (when it involves the use of the published poetry of others) and, on the other hand, a form of therapeutic writing (when it involves the act of writing original poetry.)

\section{Writing for wellbeing}

McArdle and Byrt (2001) define expressive writing as "the use of writing to enable people with mental health problems to enjoy and express themselves, develop creativity and empowerment, affirm identify and give voice to views and experiences" (p.517). Of course, there is no reason why the target group has to be only people with mental health problems. We can all benefit from opportunities to enjoy and express ourselves and to develop creativity. However, there are significant differences between a group where people can safely enjoy self-expression and the kind of expressive writing Pennebaker (2002) examined. Enjoyment does not necessarily accompany the expression of important personal experiences. Indeed Pennebaker and Segal (1999) note that, in the hours after writing, the participants in their study who wrote about traumatic life events tended to feel - perhaps unsurprisingly - more unhappy and distressed.

If writing can have a short-term negative effect on mood one might hesitate to recommend expressive writing as a way of promoting wellbeing. Pennebaker and Segal, though, found the longer-term benefits of improved physical and mental health were discerned only in the group who had written about their thoughts and feelings. The control group (who who had written about trivial, non-emotional topics) did not benefit significantly. Confronting traumatic experiences through writing, they concluded, had a salutary effect on health. They also 
suggest that, notwithstanding the value placed on self-expression by dance, music and art therapists, there is little evidence that simple catharsis or the venting of emotions in the absence of cognitive processing would achieve the same health benefits (Lewis \& Bucher, 1992). According to Pennebaker and Segal, it is in the act of constructing a story - creating a narrative that helps organise the emotional effects of experiences - that the therapeutic effects emerge.

McArdle and Byrt's (2001) definition of expressive writing - as something that enables people with mental health problems to enjoy and express themselves and to develop creativity and empowerment - differs from Pennebaker's (2002) in that it associates its use with disempowered mental health service users (as contrasted with the healthy, relatively privileged population of Pennebaker's study.) McArdle and Byrt acknowledge that expressive writing and reading can be enjoyable and beneficial and provide examples where "lighthearted self-expression" (p.518) was the aim. While this is far from Pennebaker and Segal's idea of expressive writing (involving confronting and cognitively processing trauma), "lighthearted self-expression" fits well with my own model of creative mental health care (see Figure 2) wherein the novelty, effectiveness and ethicality that make up creativity are held in balance with discipline and playfulness (Gillam, 2018).

\section{Conclusion}

There is growing evidence that participation in creative arts activities has health and wellbeing benefits for those living with mental health problems and the wider community. If nurses and other mental health professionals are to play a full role in facilitating flourishing then they need to learn more about this resource, become involved and encourage others to do so. It is important creative arts activities should be participatory so they become a vehicle not only for self-expression but for participation in groups and communities, increasing connectedness and social inclusion.

Intuitively - and judging by the evidence - participatory arts have great potential for individual and community wellbeing. To quote McNiff (2004, p.5) once more, in conclusion: "The way in which art heals within daily life is not far removed from the therapeutic transformations of 
creativity that we first explored with chronically ill people in the back wards of psychiatric hospitals... Many of us explore the healing power of art on our own, while others do it with the guidance and in the safety of therapeutic relationships... Wherever the soul is in need, art presents itself as a resourceful healer."

\section{References}

Chandler, G. E. (1999). A creative writing program to enhance self-esteem a self-efficacy in adolescents. Journal of Child \& Adolescent Psychiatric Nursing, 12 (2), 70-78.

Cohen, L. J. (1994). Bibliotherapy: a valid treatment modality. Journal of Psychosocial Nursing and Mental Health Services, 32 (9), 40-44.

Department of Health (2011). No health without mental health: A cross-government mental health outcomes strategy for people of all ages. London: Department of Health.

Gillam, T. (2002). Reflections on community psychiatric nursing. London: Routledge.

Gillam, T. (2018). Creativity, wellbeing and mental health practice. Basingstoke: Palgrave Macmillan.

Gillispie, C. (2003). A case report illustrating the use of creative writing as a therapeutic recreation intervention in a dual-diagnosis residential treatment center. Therapeutic Recreation Journal, 37 (4), 339-348.

Griffiths, S. (2003). Arts and creativity: a mental health promotion tool for young African and Caribbean men. Mental Health Review, 8 (3), 26-30.

Jindal-Snape, D., Morris, J., Kroll, T. et al. (2014). A Narrative Synthesis of Evidence Relating to the Impact of Arts and Community-Based Arts Interventions on Health, Wellbeing and Educational Attainment (Systematic Literature Reviews, Work Packages 1, 2 and 3)'. Glasgow: Glasgow Centre for Population Health.

Jones, P. (2005). The arts therapies: a revolution in healthcare. Hove: Brunner-Routledge.

Keyes, C.L. (2002). The mental health continuum: From languishing to flourishing in life. Journal of Health and Behavior Research, 43, 207-222. 
Leckey, J. (2011). The therapeutic effectiveness of creative activities on mental well-being: a systematic review of the literature. Journal of Psychiatric and Mental Health Nursing, 18 (6), 501-509.

Lepore, S.J. \& Smyth, J.M. (Eds) (2002). The writing cure: how expressive writing promotes health and emotional well-being. Washington: American Psychological Association.

Lewis, L., Tew, J., Ecclestone, K. and Spandler, H. (2016). Mutuality, Wellbeing and Mental Health Recovery: Exploring the roles of creative arts adult community learning and participatory arts initiatives. London: Arts and Humanities Research Council.

Lewis, W.A. and Bucher, A.M. (1992). Anger, catharsis, the reformulated frustrationaggression hypothesis, and health consequences. Psychotherapy, 29, 385-392.

LifeSpeaks Poetry Therapy (2017). What is poetry therapy? Retrieved from http://www.lifespeakspoetrytherapy.com/poetry-therapy/

Macpherson, H., Hart, A. and Heaver, B. (2012). Building resilience through community arts practice [Project Report]. Brighton: Arts \& Humanities Research Council Connected Communities.

McArdle, S. and Byrt, R. (2001). Fiction, poetry and mental health: expressive and therapeutic uses of literature. Journal of Psychiatric and Mental Health Nursing, 8, 517-524.

McLean, J., Woodhouse, A., Goldie, I., Chylarova, E. and Williamson, T. (2011). An Evidence Review on the Impact of Participatory Arts on Older People. London: Mental Health Foundation.

National Association for Poetry Therapy (2017). History of NAPT. Retrieved from http://poetrytherapy.org/index.php/about-napt/history-of-napt/

McNiff, S. (2004). Art heals: How creativity cures the soul. Boston, Massachusetts: Shambala Publications.

Office of the Deputy Prime Minister (2004). Mental health and social exclusion - Social Exclusion Unit Report. London: HMSO.

Pennebaker, J.W. and Segal, J.D. (1999). Forming a story: The health benefits of narrative. Journal of Clinical Psychology, 55 (10), 1243-1254. 
Pennebaker, J.W. (2002). Writing, social processes and psychotherapy: from past to future. In Lepore, S.J. and Smyth, J.M. (Eds.) (2002). The writing cure: how expressive writing promotes health and emotional well-being. Washington: American Psychological Association.

Saunders, P. (2006). Silent no more: Older adults as poets. Creative writing as a preventative approach to cognitive decline of the elderly. Ann Arbor, MI: UMI Dissertation Services.

Smith, S.B. (2008). This sylvan game: creative writing and GP wellbeing. Australian Family Physician, 37 (6), 461-462.

Sparks, L. P. (2008). The creative writing process as a means for a woman inmate to cope with her incarceration, rehabilitate herself within the prison setting, and prepare for her reentry into society. Arkansas: University of Arkansas.

Stickley, T., Wright, N. and Slade M. (2018). The art of recovery: outcomes from participatory arts activities for people using mental health services. Journal of Mental Health. Feb 15:1-7. doi: 10.1080/09638237.2018.1437609. [Epub ahead of print]. Available at: https://www.tandfonline.com/doi/full/10.1080/09638237.2018.1437609

Swann, J. (2009). Creative writing in care homes: getting started. Nursing and Residential Care, 11 (6), 306-9.

van der Steen J.T., Smaling H.J.A., van der Wouden J.C., Bruinsma M.S., Scholten R.J.P.M. and Vink, A.C. (2018). Music-based therapeutic interventions for people with dementia. Cochrane Database of Systematic Reviews 7. Art. No.: CD003477. DOI: 10.1002/14651858.CD003477.pub4. 
Figure 1. The mental health and wellbeing continua

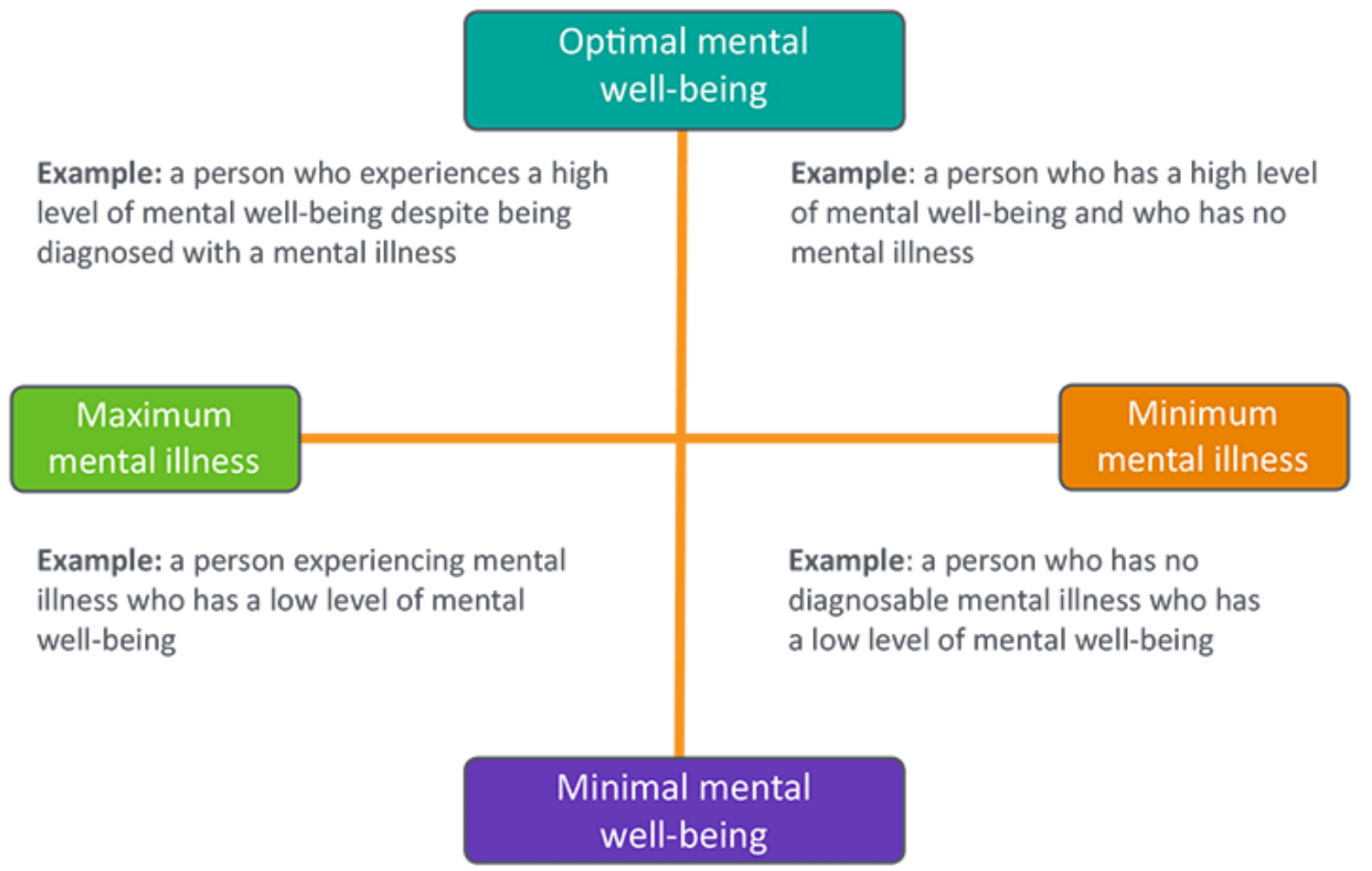

Adapted from Keyes (2002) 
Figure 2. A model of creative mental health care

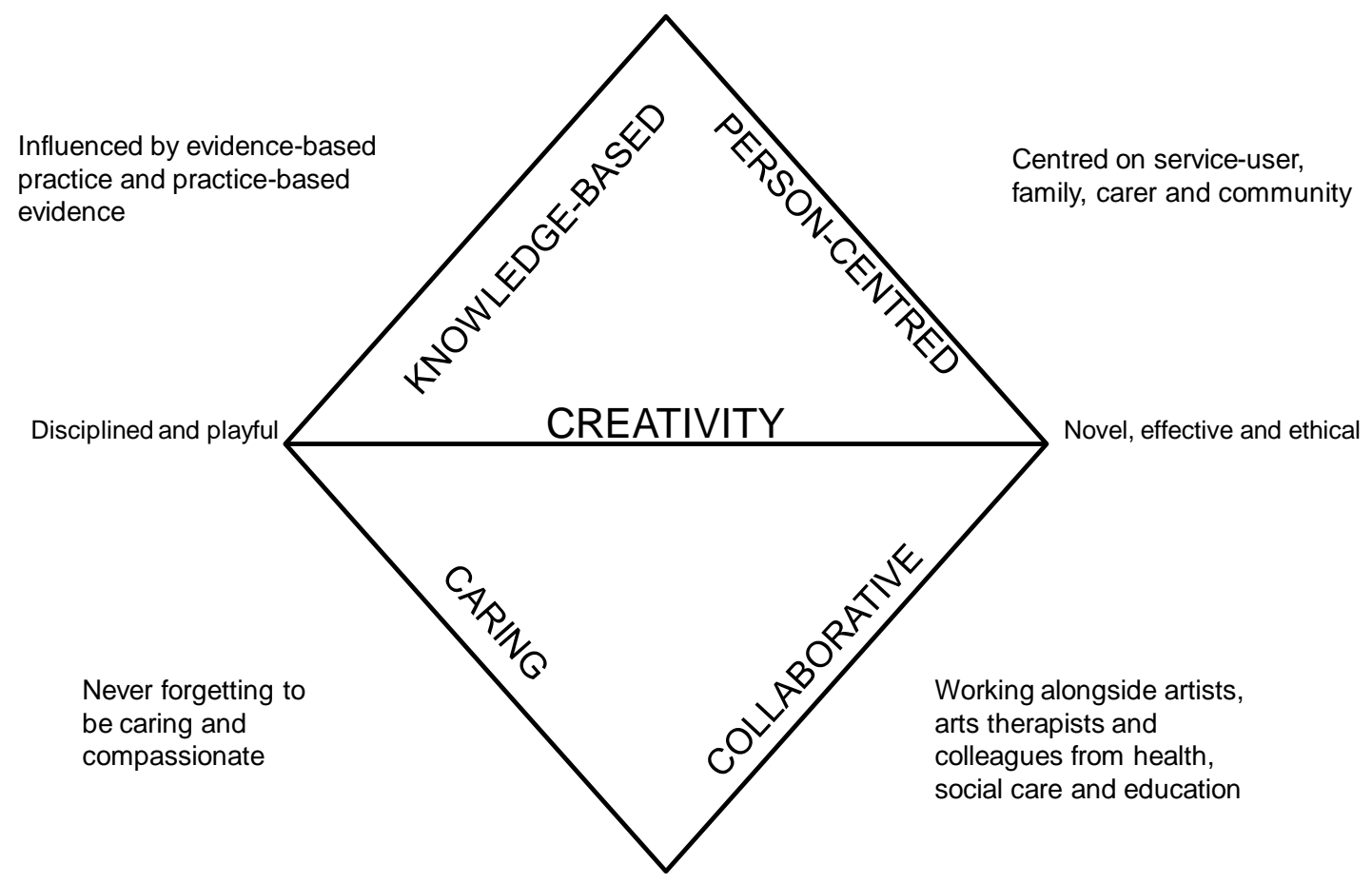

Adapted from Gillam (2018) 